\title{
VIRTUAL REALITY IN PRODUCT USABILITY TESTING: A REVIEW OF RECENT PATENTS
}

Fabio V. de Freitas ${ }^{a}$, Ingrid Winkler ${ }^{a, b}$, Marcus V. Mendes Gomes ${ }^{a, c}$, Henrique N. Nunes de Oliveira

a Centro Universitário SENAI-CIMATEC, Salvador, Brazil

${ }^{b}$ Dpt. de Modelagem Computacional

${ }^{c}$ Dpt. Indústria Criativa

\begin{abstract}
Virtual reality (VR) technology is applied to product development process and supports evaluation of product usability. This study aims to analyze findings from technological mapping research of VR in use for usability testing on products. Through the investigation of the patenting activity on Derwent Innovation database, this study describes the technological progress of this subject, the patent filing tendencies, their areas of application and details the inventions related to usability testing. Among the 161 patents fillings found, two patents have correlation between VR and usability testing of products. Therefore, opportunities are available for researches related to virtual reality and usability testing for products under development.
\end{abstract}

Keywords: Virtual Reality; Usability; Product.

\section{REALIDADE VIRTUAL EM TESTES DE USABILIDADE DE PRODUTO: UMA REVISÃO DE PATENTES}

Resumo: A realidade virtual $(\mathrm{RV})$ é uma tecnologia aplicada ao processo de desenvolvimento de produto e suporta as avaliações da usabilidade do produto. $O$ objetivo deste estudo é analisar os resultados do mapeamento tecnológico do uso RV em testes de usabilidade em produtos. Por meio da investigação das atividades de patentes encontradas no banco de dados Derwent Innovation, o estudo descreve o progresso tecnológico do tema, as tendências do depósito de patentes, suas áreas de aplicação e detalha as invenções relacionadas aos testes de usabilidade em produtos. Entre as 161 patentes encontradas, duas apresentam relação entre RV com avaliação de usabilidade de produtos. Portanto, oportunidades estão disponíveis para pesquisas envolvendo a realidade virtual e testes de usabilidade em produtos.

Palavras-Chave: Realidade Virtual; Usabilidade; Produto. 


\section{INTRODUCTION}

According to the design process of a product, several steps must be accomplished in order to ensure that the final product meets the needs of consumers while being successfully accepted by the market [1]. Therefore efforts to improve product quality, supported by technological evolution, are perpetual in companies [2]. Among the strategies adopted, the usability of the product is a factor of competitiveness, differentiation, and good practices [3]. The International Organization for Standardization (ISO), standard number 9241-11, defines usability as "the extent to which a system, product or service can be used by specified users to achieve specified goals with effectiveness, efficiency and satisfaction in a specified context of use" [4]. The usability of a product is pleasant when its interactions require less effort by the user. A satisfactory level of experience is reached when actions such as turning on a TV set and increasing its volume level are accomplished efficiently, according to the user's expectations [5].

Companies adopt prototypes in usability testing to identify problems and to seek corrections in an agile way and lower costs, reducing the risks of negative perception when the product is already in the market [6]. These usability tests follow protocols as participants are invited to interact with the system. While a moderator collects quantitative and qualitative metrics: errors committed by users, total time to complete a task, experience satisfaction survey and analysis of the user's behavior during the execution of the task [7]. This allows for measurement of the efficiency, effectiveness and satisfaction of the usability of the product [8].

In most cases, manufacturing physical prototypes is expensive and requires time despite its benefits. Additionally, once ready, they usually require reworks for updates from design changes [2]. On the other hand, virtual reality (VR), augmented reality and technologies for tracking the user's body and eyes movements can positively increase realistic immersion experience [9]. Virtual reality has been used for verification, simulation and interaction with virtual products. By reducing the use of physical prototypes, this technology enables cost benefits and agility in the development processes [10].

Usability testing's degree of accuracy has been investigated using the product's prototype in a real environment with real conditions of use while being compared to its representation in virtual reality. Studies [2] [11] indicate that design methodology should incorporate virtual reality for usability testing due to significant cost reduction when compared to physical prototypes. However, researchers [12] indicate technological constraints, such as lack of resolution and image processing capacity, that make it difficult for users to adapt to the devices in the virtual environment influencing the testing results. The criticism is based on findings in which some studies have methodological inconsistencies, influencing the conclusions and correlations of usability testing results in physical prototypes with their virtual representations. In some cases, the participants had prior knowledge about the systems being evaluated biasing further analyses on the ease of use in a virtual environment [9].

In this context, this study aims to analyze findings from technological mapping research of VR in use for usability testing on products. 


\section{METHODOLOGY}

The research methodology is based [13], in which patents published around the globe are registered and could be found on databases. To survey the patents, the Derwent Innovation database was used, and the selected key keywords were: "Virtual Reality", "Usability", "Usability Evaluation”, "Usability Testing", "Usability Engineering”, and "Product". These words were combined on different searches and the numbers of patents are described as shown in Table 1.

The string used on the Derwent innovation database was: ("Virtual Reality") AND ("Usability Engineering" OR "Usability Evaluation" OR "Usability Testing"), and the time period on the search was limited to 25 years, from 1995 until 2020.

Table 1. List of terms combination for Patent search on Derwent Innovation

\begin{tabular}{|c|l|c|c|}
\hline Combination & \multicolumn{1}{|c|}{ String } & $\begin{array}{c}\text { Number } \\
\text { of Patents }\end{array}$ & $\begin{array}{c}\text { Patents } \\
\text { Alive }\end{array}$ \\
\hline 1 & Virtual Reality AND Usability & 32,607 & 12,321 \\
\hline 2 & Virtual Reality AND Usability Testing & 287 & 107 \\
\hline 3 & Virtual Reality AND Usability Evaluation & 42 & 18 \\
\hline 4 & $\begin{array}{l}\text { Virtual Reality AND Usability } \\
\text { Engineering }\end{array}$ & 68 & 30 \\
\hline 5 & Virtual Reality AND Product & 137,368 & 50,548 \\
\hline 7 & $\begin{array}{l}\text { Virtual Reality AND usability } \\
\text { engineering OR usability evaluation } \\
\text { OR usability testing }\end{array}$ & $\mathbf{3 9 1}$ & $\mathbf{1 6 1}$ \\
\hline 8 & $\begin{array}{l}\text { Virtual Reality AND Product AND } \\
\text { Usability Engineering OR Usability } \\
\text { Evaluation OR Usability Testing }\end{array}$ & 366 & 146 \\
\hline
\end{tabular}

The results of total 391 patents filling, for the combination number seven were selected to be investigated. Analyzing the status of those patents, only 161 registrations are alive at the present moment. In the next sections, the selected patents are reviewed.

\section{RESULTS AND DISCUSSION}

The results were organized in four different sections: Annual Publishing of Patents, Patents Origin Location, International Patent Classification(IPC), Cooperative Patent Classification(CPC) and Patent Profiles.

\subsection{Annual Publishing of Patents}

The Fig. 1 shows the annual publishing of patents, the trends on number of patent publications from 2001 to 2020, pointing out three time periods. The first-period ranges from 2001 to 2005 , when a certain linearity in the number of published patents is noticed. From 2006 to 2014 there is an increase in publications. 
From 2015 to 2020, at last, there was a significant increase in patents, an average number of 13 annual patents filling per year and with its peak of publications in 2017: 28 patents registered. This occurrence happens nearly when researches about virtual reality increase, mainly for Computer Science and Engineering fields. According to [14], 2016 was the year with highest number of researches about virtual reality worldwide. The trend was interrupted in 2018, when the number of patents fillings was 14 , and it remains without significant changes until the present moment.

Figure 1. Annual Publishing of Patents

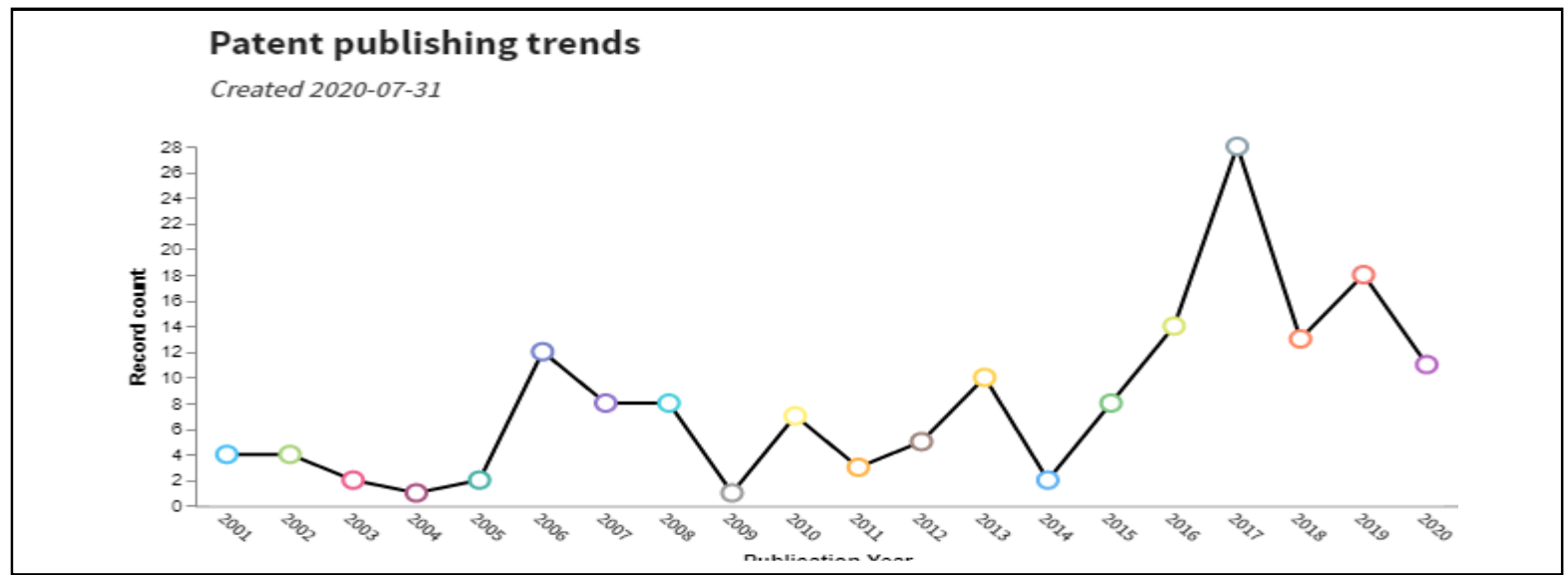

\subsection{Patents Origin Location}

The Fig. 2 maps patents by countries. The United States significantly leads the inventions in this field of technology. However, it is noteworthy that powerful and technologically capable countries, such as China and Japan, together have no more than $8 \%$ of registered patents.

Figure 2. Registered Patents by country

United States (50.61\%)

W.I.P.O (P.C.T.) (18.81\%)

- European Patent Office (6.57\%)

- Australia (6.42\%)

- China $(5.5 \%)$

- Canada (3.98\%)

Republic of Korea (3.06\%)

Japan (2.29\%)

- Singapore $(0.46 \%)$

India $(0.46 \%)$

- Germany $(0.46 \%)$

- United Kingdom (0.31\%)

and 7 more
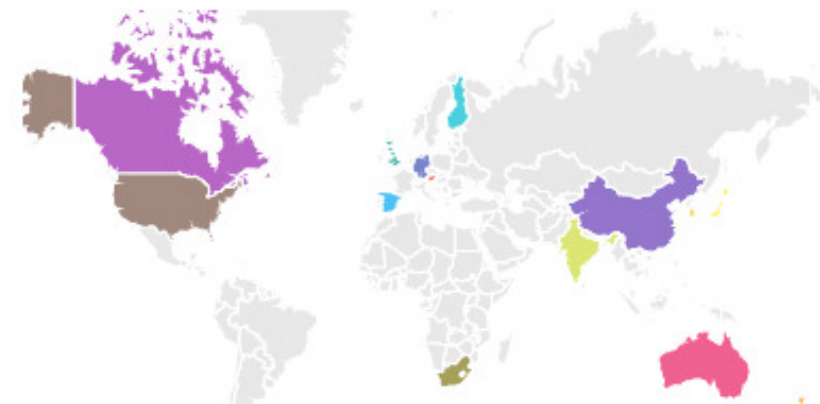

Regions

\subsection{International Patent Classification}

International Patent classification (IPC) is the form to stablish a common code for registered patents, therefore, facilitating the search and access the technological information available in the documents related to the same field [15]. 
The main classifications found for the selected documents are: A63 (sports, games and amusements), G06 (computing and calculation or counting) and G09 (educating, cryptography, display, advertising and seals). The Fig. 3 shows the complete codes by classification, and its sub-classes. and its details is described as the following: "Input arrangements for transferring data to be processed into a form capable of being handled by the computer; Output arrangements for transferring data from processing unit to output unit, e.g. interface arrangements".

Figure 3. International Patent Classification (IPC)

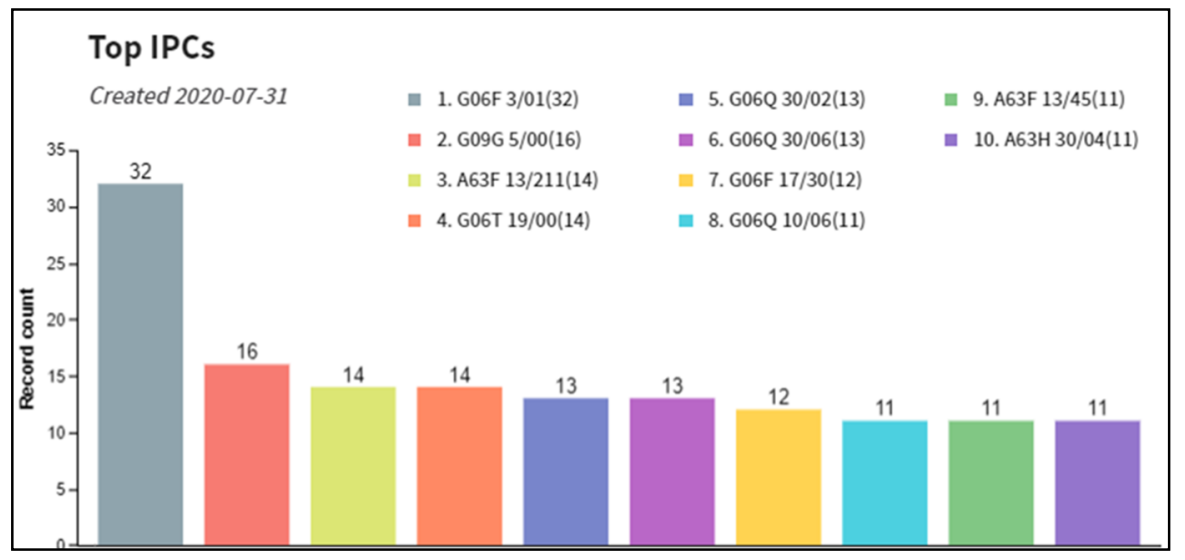

\subsection{Cooperative Patent Classification}

Similar to IPC, the Cooperative Patent Classification (CPC) is an arrangement of patents by codes, which were created from the cooperation between European Patent Offices (EPO) and North America Patent and Trademark Office (USPTO).

Patents were spotted on "Physics" and "Human necessities" fields, on subclasses G06F (electric digital data processing), A63H (toys) and A63F (cardboard, or roulette games, indoor games using small moving playing bodies, video games and games not otherwise provided for). The Fig. 4 shows the number of patents fillings by CPC. The top sections of the arrangement by quantity of the publications is G06 F $3 / 04815$, described as "interaction with three-dimensional environments, e.g. control of viewpoint to navigate in the environment"[15], followed by section G06F 3/012, described as "Head tracking input arrangements, e.g. Head-Mounted Display".

Figure 4. Cooperative Patent Classification (CPC)

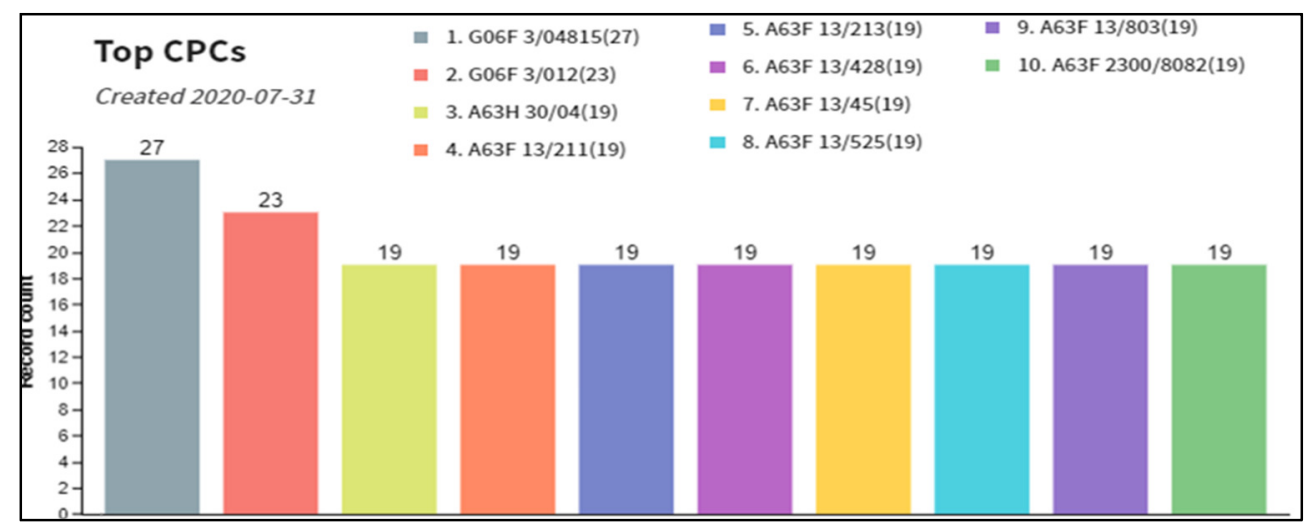




\subsection{Recent patents on usability testing with based on VR}

From the 161 selected patents found, as showed in the Fig. 5, over the last four years, the technological area with the most significant presence in number of patents filling related to virtual reality technology and usability tests methods is related to the following fields: Computing, Transitory, Touch, Information Processing, User, Virtual, Management.

Figure 5. Technologies under development

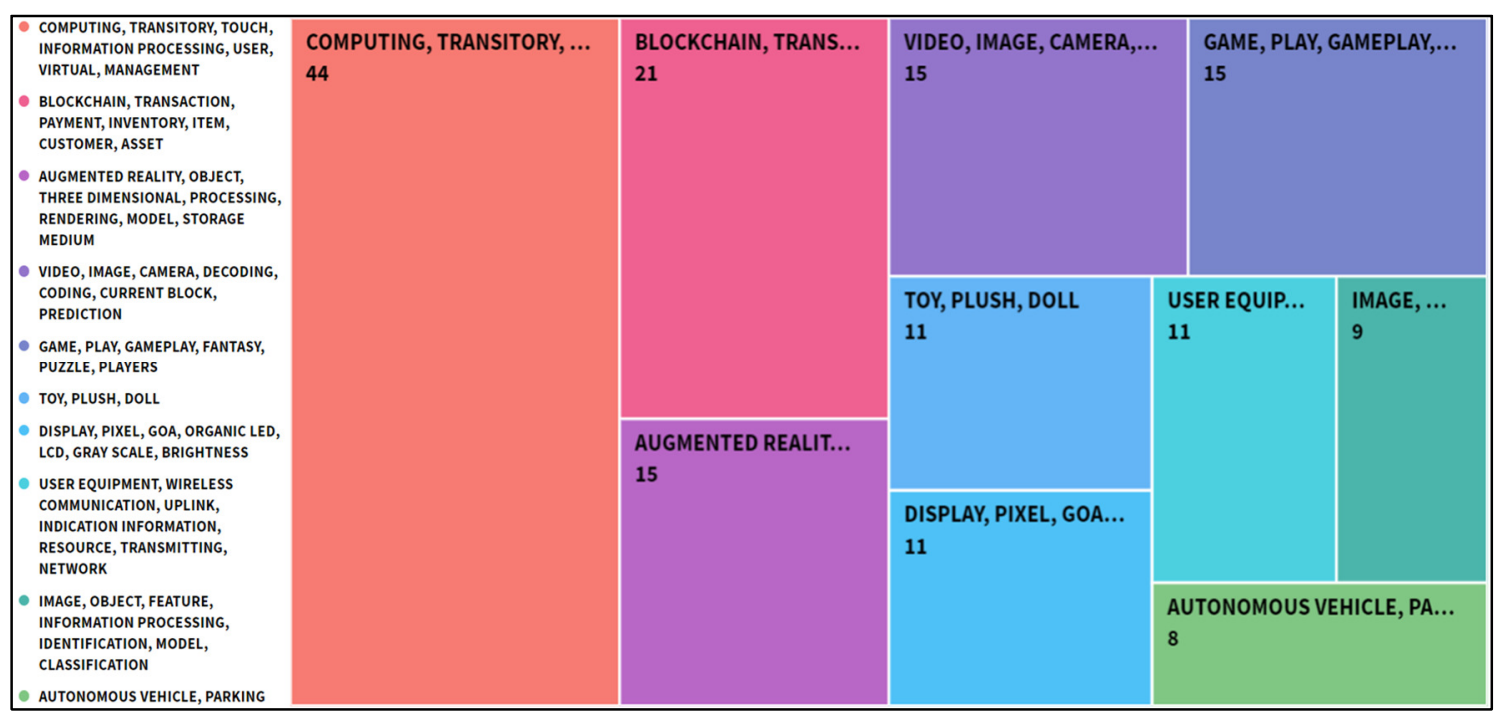

Regarding this study focus, only two patents are related to virtual reality technology and usability testing of products, the registered inventions KR2019088710A and CN111414084A. Both registrations were made by Chinese institutions in 2019 and 2020. Their current status is "undefined" which means that the documents are likely under final process for approval.

The original patent document KR2019088710A (2019) is described as "the method evaluate vehicle system virtual design drive environment". This method for evaluation of usability for vehicle infotainment system involves providing interactions between different virtual infotainment systems and drivers at a virtual driving environment while evaluating usability of infotainment systems for vehicles [16].

Usability of a virtual infotainment system is evaluated by measuring both the execution time of the operation command and the running state of a virtual vehicle according to execution of the operation command. The running state of the virtual vehicle is included with speed of the virtual vehicle, distance of a preceding vehicle, a distance between the lane and the virtual vehicle and the steering angle of the virtual vehicle during execution of an operating instruction of the drive [16].

The patent description for CN111414084A (2020) reveals the invention as not being a product: it is a space testing laboratory which comprises an area with the display of three-dimensional models based on data collected from virtual technology user experience. The experience data of test users is collected during the test process in which the observer is allowed to monitor the test process of the test user and perform a synchronous experience. The central control system is used to analyze the space 
usability test results according to the data collected. The test area has an immersive projection display system and a spatial positioning system, a tracking interaction system for data generated by the test user during the test process [17].

\section{CONCLUSION}

Reviewing these recent papers, patent fillings per year indicate that, even though an increase occurred since 2014, the present scenario seems to be stationary in numbers of patents registered on this field.

Among the 161 documents identified, only two of them combine virtual reality and usability methods applied for products under development. Based on the status information found, both patent requests for approval are recent process, and it could demonstrate that subject was not well investigated in the past.

The researchers can explore the technological gap found, increasing the scientific knowledge within vast possibilities for the development of applications. Base on that, there are substantial opportunities to innovate and implement valuable process as well as products.

As described for some studies on this field, the application of virtual reality on the product development is a positive factor for gaining agility. In addition, when it is not limited for product design purposes, and its used is expanded, for instance, for verification of usability of the products, then the technology could increase the benefits as cost and time savings during product development.

\section{REFERENCE}

${ }^{1}$ FALCÃO, Christianne Soares; SOARES, Marcelo Márcio. Application of virtual reality technologies in consumer product usability. In: International Conference of Design, User Experience, and Usability. Springer, Berlin, Heidelberg, 2013. p. 342-351.

2FALCÃO, Christianne; SOARES, Marcelo. Usabilidade de Produtos de Consumo: uma análise dos conceitos, métodos e aplicações. Estudos em Design, v. 21, n. 2, 2013.

${ }^{3}$ ACOSTA, Gabriel et al. Addressing human factors and ergonomics in design process, product life cycle, and innovation: trends in consumer product design. Human Factors and Ergonomics in Consumer Product Design: Methods and Techniques, p. 133-154, 2011

${ }^{4}$ ISO, SFSEN. 9241-11 (1998). Ergonomic requirements for office work with visual display terminals (VDTs)-Part II guidance on usability, 1998.

5JORDAN, Patrick W. An introduction to usability. CRC Press, 1998.

${ }^{6}$ BRUNO, Fabio et al. Mixed prototyping environment with different video tracking techniques. In: IMProVe 2011 International Conference on Innovative Methods in Product Design. 2011. p. 105-113 
${ }^{7}$ DE FRANÇA, Ana Carol Pontes; NETO, J. Pereira; SOARES, Marcelo Márcio. Methods and procedures to usability testing in virtual reality systems. In: International Conference on Applied Human Factors and Ergonomics. Springer, Cham, 2017. p. 4551.

${ }^{8}$ SALVENDY, Gavriel (Ed.). Handbook of human factors and ergonomics. John Wiley \& Sons, 2012

${ }^{9}$ BOLDER, Anna; GRÜNVOGEL, Stefan M.; ANGELESCU, Emanuel. Comparison of the usability of a car infotainment system in a mixed reality environment and in a real car. In: Proceedings of the 24th ACM Symposium on Virtual Reality Software and Technology. 2018. p. 1-10.

${ }^{10}$ ZIMMERMANN, Peter. Virtual reality aided design. A survey of the use of VR in automotive industry. In: Product Engineering. Springer, Dordrecht, 2008. p. 277-296.

${ }^{11}$ Ma C., Han T. (2019) Combining Virtual Reality (VR) Technology with Physical Models - A New Way for Human-Vehicle Interaction Simulation and Usability Evaluation. In: Krömker H. (eds) $\mathrm{HCl}$ in Mobility, Transport, and Automotive Systems. HCII 2019. Lecture Notes in Computer Science, vol 11596. Springer, Cham

${ }^{12}$ PETTERSSON, Ingrid; KARLSSON, MariAnne; GHIURAU, Florin Timotei. Virtually the Same Experience? Learning from User Experience Evaluation of In-vehicle Systems in VR and in the Field. In: Proceedings of the 2019 on Designing Interactive Systems Conference. 2019. p. 463473.

${ }^{13}$ de Lima Silva, V., Oliveira, T. S., de Souza, C. O., Druzian, J. I., Machado, B. A. S., Nunes, I. L., \& Ribeiro, C. D. F. (2020). Technological Prospection of Oil Nanoparticles: Primary Characteristics and Profiles. Recent Patents on Nanotechnology.

${ }^{14}$ ZENG, Li et al. Landscapes and Emerging Trends of Virtual Reality in Recent 30 Years: A Bibliometric Analysis. In: 2018 IEEE SmartWorld, Ubiquitous Intelligence \& Computing, Advanced \& Trusted Computing, Scalable Computing \& Communications, Cloud \& Big Data Computing, Internet of People and Smart City Innovation (SmartWorld/SCALCOM/UIC/ATC/CBDCom/IOP/SCI). IEEE, 2018. p. 1852-1858.

${ }^{15}$ PIRES, Edilson Araújo; RIBEIRO, Nubia Moura; QUINTELLA, Cristina M. Sistemas de Busca de Patentes: análise comparativa entre Espacenet, Patentscope, Google Patents, Lens, Derwent Innovation Index e Orbit Intelligence. Cadernos de Prospecção, v. 13, n. 1, p. 13,2020

${ }^{16}$ Hokyoung Blake Ryu. Method for evaluating usability on vehicle infotainment system, method for evaluating cognitive load of driver using vehicle infotainment system KR2019088710A Patent filing July-29-2019

${ }^{17}$ REN, Zhi-ming. Space availability test laboratory and using method and device thereof. CN202010261214A. Patent filing: July-14-2020 